Original Research Paper

\title{
A Brief Introduction to the Bird Strike Numerical Simulation
}

\author{
Aniello Riccio, Roberta Cristiano and Salvatore Saputo \\ Department of Industrial and Informatics Engineering, Second University of Naples, Aversa (CE), Italy
}

Article history

Received: 17-10-2016

Revised: $29-10-2016$

Accepted: 03-11-2016

Corresponding Author:

Aniello Riccio

Department of Industrial and

Informatics Engineering,

Second University of Naples,

Aversa (CE), Italy

Email: aniello.riccio@unina2.it

\begin{abstract}
Bird impacts can be extremely critical events for the air transport safety. Since aircraft structures have become more and more complex components, the numerical prediction of the damage onset and evolution induced by a bird impact has become a very challenging task. The aim of this work is to provide a brief overview of the numerical techniques adopted for the prediction of the bird impact phenomenon on a leading edge of a regional aircraft wing. Smooth Particle Hydrodynamics (SPH), Rigid and Lagrangian models have been investigated and the results have been compared and critically assessed.
\end{abstract}

Keywords: Bird Strike, SPH, FEM Analysis

\section{Introduction}

Bird strikes on airplanes can be very dangerous events, which are becoming more and more common due to the increasing in air traffic (Georgiadis et al., 2008). According to certification requirements, aeronautical structures must be able to withstand bird strikes events, ensuring the global structural integrity and the passengers' safety. Due to the high relative velocity between the bird and the airplane, bird strike event can be surely classified as high velocity impact events, even if a true classification of the impact events on the base of their velocity and energy is a very challenging task (Riccio et al., 2016a; Caputo et al., 2013; Riccio et al., 2016b).

Several works can be found in literature dealing with bird strike events and showing the effects on the most critical structural components, which can experience this phenomenon: The windshield (Plassard et al., 2015; Lu et al., 2015; Ugrcic et al., 2015) and the leading edge (Sun et al., 2010; Guida et al., 2008; Smojver and Ivancevic, 2010; Wang and Yue, 2010; Hanssen et al., 2006; Airoldi and Cacchione, 2006; Johnson and Cook, 1983; 1985; Johnson and Cook, 1985; Liu et al., 2013a; Liu and Sun, 2014; Lavoie et al., 2007a; Liu et al., 2013b; Jain and Ramachandra, 2003; Guida et al., 2011).

In order to design structures able to tolerate bird strike, the knowledge about impact phenomena should be improved by means of experimental observations and numerical simulations. Since impact experimental tests, representative of bird strike events, can be very costly and time consuming, it becomes mandatory to develop numerical Finite Element Models able to predict the high velocity impact phenomena on the aircraft structure (Guida et al., 2008; Smojver and Ivančević, 2010; Wang and Yue, 2010). In the frame of the numerical simulations, several interacting aspects have to be considered, such as damage initiation and accumulation (Johnson and Cook, 1983; 1985; Xue and Wierzbicki, 2009; Liu et al., 2013a; Liu and Sun, 2014), contact behavior (Johnson and Cook, 1983; 1985) and bird modelling approaches (Lavoie et al., 2007a; Liu et al., 2013b; Jain and Ramachandra, 2003; Guida et al., 2011; Liu et al., 2008).

Bird strike on metallic leading edge is usually simulated by means of a progressive dynamic failure analysis adopting a Johnson-Cook (J-C) constitutive material model (Johnson and Cook, 1983; 1985). Alternative approaches taking into account the influence of both stress and strain rates on failure propagation are presented in (Sun et al., 2010; Xue and Wierzbicki, 2009; Liu et al., 2013a; Liu and Sun, 2014).

Indeed, bird material strength can be considered irrelevant if compared to the aircraft material one. Hence, bird can be considered as a soft body impacting, as a pressure flow, the impact area. The simulation with finite elements of the material deformation during soft body impacts can be characterized by excessive elements distortions when a Lagrangian (Guida et al., 2008; Smojver and Ivančević, 2010; Airoldi and Cacchione, 2006) formulation is adopted. These distortions induce excessive spurious deformation modes (hourglass) affecting the accuracy of results.

The aim of the present paper is to briefly introduce and compare the numerical approaches commonly adopted to simulate the high velocity impacts and to predict the bird impact effects on real aeronautical structure. Indeed, three different numerical approaches are investigated in the present paper: The first approach adopts rigid body elements (Hibbitt, 1984) to model the 
bird, the second approach adopts the Lagrangian theory (Lavoie-Perrier, 2008; Lavoie et al., 2007b) to take into account bird deformation during impact the last approach uses the Smooth Particle Hydrodynamic (SPH) formulation (Lavoie et al., 2007b; 2007c) to model the bird body. The SPH approach capability to bypass the Lagrangian approach limitations, in terms of elements distortions, has been assessed.

In section 2 the numerical model and the finite element implementation are briefly introduced while in section 3 the most relevant results are presented. Finally in section 4 the results are critically assessed.

\section{Numerical Model and Finite Element Implementation}

\section{Wing FEM Model}

The investigated aeronautical structure is an Aluminium 7075-T6 wing section of a regional aircraft. ABAQUS explicit Finite Element Code has been used for the numerical simulations. The FEM model of the wing section has been made of shell elements without considering material failure criteria. The wing section, whose dimensions are reported in Table 1, has been clamped on both external edges along y direction, according to Fig. 1.

The whole wing section model has been discretized using 51568 full integration point shell elements S4. The actual thickness of the wing section components has been taken into account by means of different offsets. Surface to surface tie constraints, available in ABAQUS, have been adopted to connect the differently meshed parts with a self-contact interactions law based on a penalty contact based algorithm; furthermore, an average 0.5 friction coefficient has been considered in sliding contact to account for the roughness of contacting surfaces. Figure 2 shows a fully description of the wing section components.

\section{Bird Model}

A $150 \mathrm{~m} / \mathrm{s}$ velocity impact has been considered. It was found that the most appropriate substitute material for the bird during a high velocity impact event, is the gelatine with $10 \%$ porosity and $950 \mathrm{~kg} / \mathrm{m}^{3}$ density. While the better geometrical shape is a cylinder with hemispherical ends and a length to radius ratio equal to two, since this shape shows the real bird pressure time history during the impact tests as declared in (Ugrcic et al., 2015). The bird material density has been reduced to be $938 \mathrm{~kg} / \mathrm{m}^{3}$, as suggested in (Liu et al., 2008). Hence, the numerical model of the bird, characterised by the following dimensions, is shown in Fig. 3:

- $\quad \mathrm{Lb}=228 \mathrm{~mm}$, bird structure length

- $\Phi=114 \mathrm{~mm}$, bird structure diameter
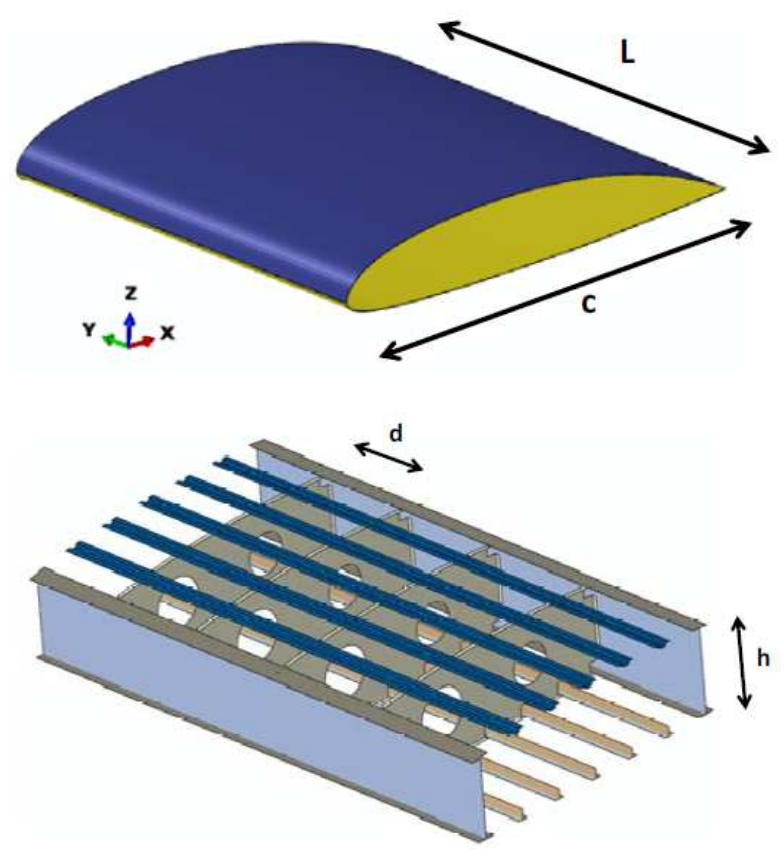

Fig. 1. Wing section structure

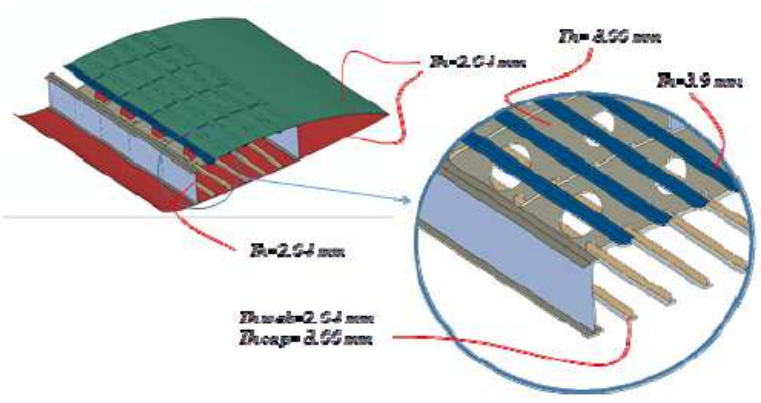

Fig. 2. Wing section thicknesses

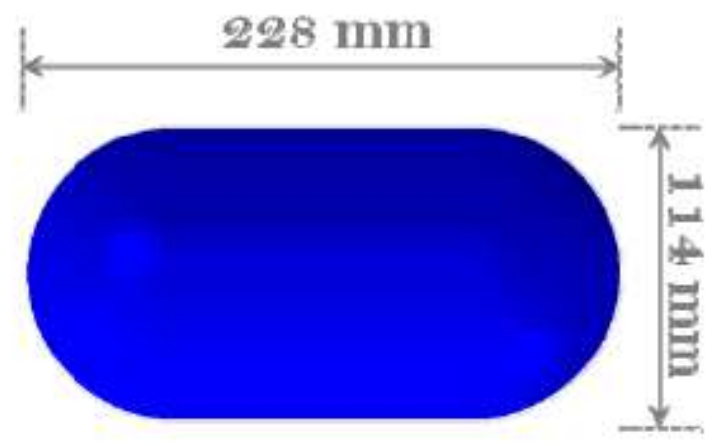

Fig. 3. Bird structure

Table 1. Section Wing dimensions

\begin{tabular}{ll}
\hline Section wing length (L) & $2.71 \times 10^{3} \mathrm{~mm}$ \\
Airfoil profile chord (c) & $3.10 \times 10^{3} \mathrm{~mm}$ \\
Wing ribs interaxle spacing (d) & $5.92 \times 10^{2} \mathrm{~mm}$ \\
Wing rib height (h) & $4.23 \times 10^{2} \mathrm{~mm}$ \\
\hline
\end{tabular}




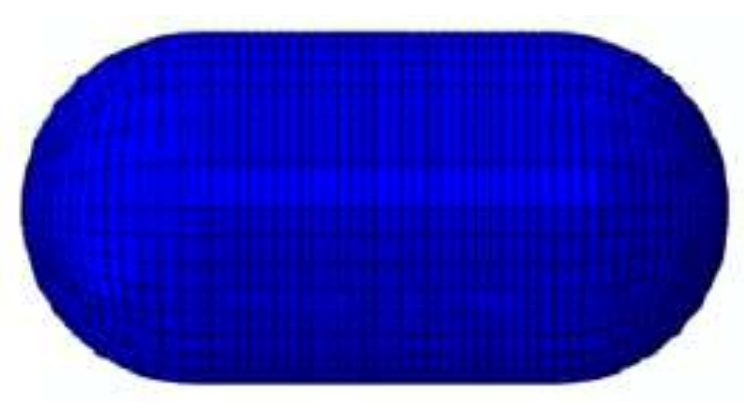

Fig. 4. Rigid and lagrangian model

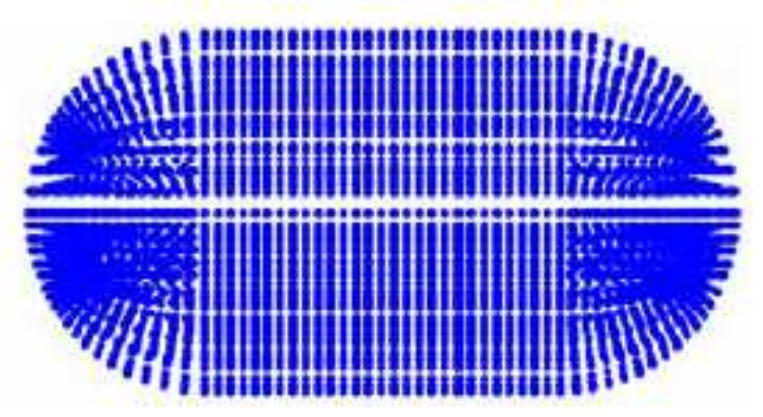

Fig. 5 SPH model

As already remarked, the bird has been modelled as an equivalent mass of water, since birds are made mostly of water and air in their bones and lungs (Georgiadis et al., 2008; Smojver and Ivančević, 2010; Lavoie et al., 2007b). The bird hydrodynamic response is studied using the Equation of State (EOS) materials which define the pressure to density ratio and the volumetric strength of the material. Relevant results for bird strike simulations can be found in (Johnson and Holzapfel, 2003) where the complex pressure field, arising in the impact region when a bird impacts a target, is introduced. The peak pressure value has the following theoretical value (Hugoniot pressure):

$P_{H}=\rho_{0} U_{S}\left(U_{0}\right) U_{0}$

where, $\rho_{0}$ is the initial material density, $U_{S}$ and $U_{0}$ are, respectively, the shock and impact velocities (Johnson and Holzapfel, 2003). After the beginning of the impact event, the maximum pressure is followed by a pressure release phase and, finally, by the development of a stable and constant pressure flow given by the following relation:

$P=\frac{1}{2} \rho_{0}\left(U_{0}\right)^{2}$

The EOS material model validation relating the impact with a rigid plate showed a good agreement with the experimental Hugoniot, theoretical and stagnation pressure time history curves, as can be seen in (Smojver and Ivančević, 2010).

As anticipated in the introduction, the bird structure has been modelled according to three different approaches: Rigid body, Lagrangian and Smooth Particle Hydrodynamics (SPH). The rigid and the Lagrangian models (Fig. 4) are modelled using standard eight node solid brick elements (C3D8R) with reduced integration to reduce the computational costs. The Lagrangian bird model is defined by considering a distortion control and a viscous hourglass control in order to avoid excessive elements distortion. The model has been validated by comparing Hugoniot and stagnation pressures developing an impact on a rigid plate at a velocity of $116 \mathrm{~m} \mathrm{~s}^{-1}$, normally to the target (Smojver and Ivančević, 2010).

According to the SPH method the bird is modelled as discrete elements considered as particles separated by a spatial distance called "smoothing length". The physical properties of the single particle are obtained by summing the all particles properties. The model is shown in Fig. 5.

\section{Results}

The results of the explicit analyses are reported in Fig. 6 where the magnitude of the impact induced displacements obtained with the different bird models introduced in the previous sections, are compared. The displacements of the leading edge obtained with rigid body bird model, the Lagrangian formulation bird model and the SPH based bird model are, respectively, reported in Fig. 6a-c. In the following section, these results are analyzed and discussed.

\section{Discussion}

According to the results shown in Fig. 6, the largest wing indentation $(0.4233 \cdot 103 \mathrm{~mm})$ has been found considering the Rigid Body approach (Fig. 6a). On the other hand, as it can be observed in Fig. 6c, the SPH model provides the lowest wing indentation $(0.1253 \cdot 102$ $\mathrm{mm})$. According to Fig. 6-b, the Lagrangian approach, adopting a homogeneous material constitutive model, shows an intermediate wing indentation $(0.3290 \cdot 103$ $\mathrm{mm})$. Indeed, according to the SPH approach, the single particles can move without interactions leading to a larger impact surface if compared to the one evaluated with a Lagrangian or rigid model. This is the reason why the wing indentation predicted by the SPH approach is smaller. In terms of computational costs, the Lagrangian approach has been found to be the less effective one while the Rigid Bird Model has revealed to be the most effective one. 
a)

\begin{tabular}{|c|}
\hline 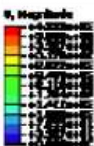 \\
\hline
\end{tabular}

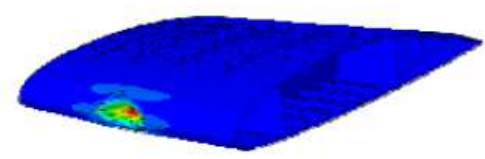

b)
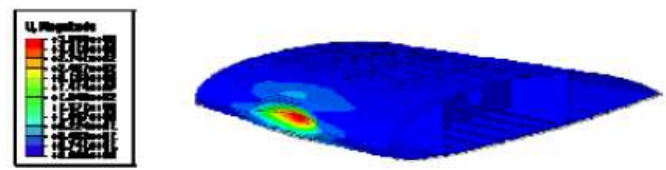

c)
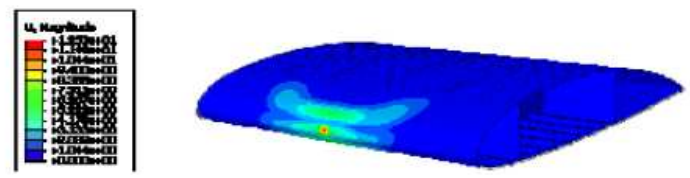

Fig. 3. (a) Rigid Body displacements; (b) Lagangian model displacements; (c) SPH model displacements

\section{Conclusion}

A numerical investigation on the bird impact phenomenon on a leading edge of a regional aircraft wing is presented in order to evaluate the bird impact effects on real aeronautical structures. Three different numerical approaches (Rigid Bird Model, Lagrangian Model and SPH Model) have been presented and compared. The results, as expected, showed a variable output in terms of wing indentation provided by the different approaches. The Lagrangian approach has been found to be the less computationally effective one, while the Rigid Bird Model has revealed to be the most computationally cheap one.

\section{Funding Information}

The authors have no support or funding to report.

\section{Author's Contributions}

All the authors contributed equally to prepare, develop and carry out this manuscript.

\section{Ethics}

This article is original. Authors declare that are not ethical issues that may arise after the publication of this manuscript.

\section{References}

Airoldi, A. and B. Cacchione, 2006. Modelling of impact forces and pressures in Lagrangian bird strike analyses. Int. J. Impact Eng., 32: 1651-1677.

DOI: 10.1016/j.ijimpeng.2005.04.011
Caputo, F., G. Lamanna, A. De Luca, R. Borrelli and S. Franchitti, 2013. Global-local FE Simulation of a plate LVI test. Struct. Durabil. Health Monitor., 9: 253-267.

Georgiadis, S., A.J. Gunnion, R.S. Thomson and B.K. Cartwright, 2008. Bird-strike simulation for certification of the Boeing 787 composite moveable trailing edge. Compos. Struct., 86: 258-268. DOI: 10.1016/j.compstruct.2008.03.025

Guida, M., F. Marulo, M. Meo and M. Riccio, 2008. Analysis of bird impact on a composite tailplane leading edge. Applied Compos. Mater., 15: 241-257. DOI: 10.1007/s10443-008-9070-6

Guida, M., F. Marulo, M. Meo, A. Grimaldi and G. Olivares, 2011. SPH - Lagrangian study of bird impact on leading edge wing. Compos. Struct., 93: 1060-1071. DOI: 10.1016/j.compstruct.2010.10.001

Hanssen, A.G., Y. Girard, L. Olovsson, T. Berstad and M. Langseth, 2006. A numerical model for bird strike of aluminium foam-based sandwich panels. Int. J. Impact Eng., 32: 1127-1144.

DOI: 10.1016/j.ijimpeng.2004.09.004

Hibbitt, 1984. Abaqus theory manual. Hibbitt, Karsson and Sorensen.

Jain, R. and K. Ramachandra, 2003. Bird impact analysis of prestressed fan blades using explicit finite element code. Proceedings of the International Gas Turbine Congress Tokyo, (TCT' 03).

Johnson, A.F. and M. Holzapfel, 2003. Modelling soft body impact on composite structures. Compos. Struct., 61: 103-113. DOI: 10.1016/S0263-8223(03)00033-3

Johnson, G.R. and W.H. Cook, 1983. A constitutive model and data for metals subjected to large strains, high strain rates and high temperatures. Proceedings of the 7 th International Symposium on Ballistics, (ISB' 83), pp: 541-547.

Johnson, G.R. and W.H. Cook, 1985. Fracture characteristics of three metals subjected to various strains, strain rates, temperatures and pressures. Eng. Fracture Mechan., 21: 31-48. DOI: $10.1016 / 0013-7944(85) 90052-9$

Lavoie, M.A., A. Gakwaya, M.N. Ensan and D.G. Zimcik, 2007a. Review of existing numerical methods and validation procedure available for bird strike modeling. Proceedings of the International Conference on Computational and Experimental Engineering and Sciences, (EES’ 07), pp: 111-118.

Lavoie, M.A., A. Gakwaya, M.N. Ensan and D.G. Zimcik, 2007b. Review of existing numerical methods and validation procedure available for bird strike modeling. Proceedings of the International Conference on Computational and Experimental Engineering and Sciences, (EES' 07), pp: 111-118.

Lavoie, M.A., A. Gakwaya, M.N. Ensan and D.G. Zimcik, 2007c. Validation of available approaches for numerical bird strike modeling tools. Int. Rev. Mech. Eng. 
Lavoie-Perrier, M.A., 2008. Soft body impact modelling and development of a suitable meshless approach. Université Laval.

Liu, J., Y.L. Li and F. Xu, 2008. The numerical simulation of a bird-impact on an aircraft windshield by using the SPH method. Adv. Mater. Res., 33: 851-856. DOI: 10.4028/www.scientific.net/AMR.33-37.851

Liu, Y., Z. Li, Q. Sun, X. Fan and W. Wang, 2013b. Separation dynamics of large-scale fairing section: A fluid-structure interaction study. Proc. Institut. Mechan. Eng., Part G: J. Aerospace Eng., 227: 1767-1779. DOI: 10.1177/0954410012462317

Liu, Y.J. and Q. Sun, 2014. A dynamic ductile fracture model on the effects of pressure, Lode angle and strain rate. Mater. Sci. Eng. A, 589: 262-270. DOI: 10.1016/j.msea.2013.09.082

Liu, Y.J., Q. Sun, X.L. Fan and T. Suo, 2013a. A stressinvariant based multi-parameters ductile progressive fracture model. Mater. Sci. Eng. A, 576: 337-345. DOI: 10.1016/j.msea.2013.04.013

Lu, Z., M. Seifert and C.H. Tho, 2015. Bird impact simulation of polycarbonate windshield subject to brittle failures. Ann. Forum Proc. AHS Int., 2: 969-975.

Plassard, F., P.L. Hereil, P. Joseph and J. Mespoulet, 2015. Experimental and numerical study of a bird strike against a windshield. Proceedings of the 11th International Conference on the Mechanical and Physical Behaviour of Materials under Dynamic Loading, (MDL' 15), EDP Sciences, pp: 1-6. DOI: $10.1051 /$ epjconf/20159401051
Riccio, A., S. Saputo and A. Sellitto, 2016. A user defined material model for the simulation of impact induced damage in composite. Key Eng. Mater., 713: 14-17. DOI: 10.4028/www.scientific.net/KEM.713.14

Riccio, A., S. Saputo, A. Sellitto, A. Raimondo and R. Ricchiuto, 2016. Numerical investigation of a stiffened panel subjected to low velocity impacts. Key Eng. Mater., 665: 277-280. DOI: 10.4028/www.scientific.net/KEM.665.277

Smojver, I. and D. Ivančević, 2010. Numerical simulation of bird strike damage prediction in airplane flap structure. Compos. Struct., 92: 2016-2026. DOI: 10.1016/j.compstruct.2009.12.006

Sun, Q., Y.J. Liu and R.H. Jin, 2010. Numerical simulation of bird strike in aircraft leading edge structure using a new dynamic failure model. Proceedings of the 29th Congress of International Council of the Aeronautical Sciences, (CAS' 14), pp: 1-19.

Ugrcic, M., S.M. Maksimović, D.P. Stamenković, K.S. Maksimović and K. Nabil, 2015. Finite element modeling of wing bird strike. FME Trans., 43: 76-81. DOI: $10.5937 /$ fmet $1501076 \mathrm{u}$

Wang, F.S. and Z.F. Yue, 2010. Numerical simulation of damage and failure in aircraft windshield structure against bird strike. Mater. Design, 31: 687-695. DOI: 10.1016/j.matdes.2009.08.029

Xue, L. and T. Wierzbicki, 2009. Numerical simulation of fracture mode transition in ductile plates. Int. J. Solids Struct., 46: 1423-1435.

DOI: 10.1016/j.ijsolstr.2008.11.009 